\title{
Management of Anticoagulant Treatment and Anticoagulation-Related Complications in Nonagenarians
}

\author{
Michela Giustozzi $^{1} \quad$ Lana A. Castellucci $^{2}$ Geoffrey D. Barnes ${ }^{3}$ \\ ${ }^{1}$ Internal Vascular and Emergency Medicine and Stroke Unit, \\ University of Perugia, Perugia, Italy \\ ${ }^{2}$ Department of Medicine, Ottawa Hospital Research Institute, \\ University of Ottawa, Ontario, Canada \\ ${ }^{3}$ Department of Internal Medicine, Frankel Cardiovascular Center, \\ Address for correspondence Michela Giustozzi, MD, Internal and \\ Cardiovascular Medicine - Stroke Unit, University of Perugia, Via G \\ Dottori 1, 06129 Perugia, Italy (e-mail: michelagiustozzi@hotmail.it; \\ michela.giustozzi@unipg.it).
} University of Michigan, Ann Arbor, Michigan, United States

Hämostaseologie 2020;40:292-300.

\begin{abstract}
Keywords

- anticoagulants

- atrial fibrillation

- nonagenarians

- oldest age

- venous thromboembolism

Given the aging population, the burden of age-dependent diseases is growing. Despite this, elderly patients are often underrepresented in clinical trials and little data are available on current anticoagulant management and outcomes in this unique population, especially those aged 90 years or older. There is uncertainty, and a fear of "doing harm," that often leads to de-prescription of antithrombotic agents in nonagenarian patients. Decision-making concerning the use of anticoagulant treatment needs to balance the risk of thrombotic events against the risk of major bleeding, especially intracranial hemorrhage. In this perspective, the development of direct oral anticoagulants (DOACs), acting as direct and selective inhibitors of a specific step or enzyme of the coagulation cascade, has dramatically changed oral anticoagulant treatment. In fact, given the lower incidence of intracranial hemorrhage, the favorable overall efficacy and safety, and the lack of routine monitoring, DOACs are the currently recommended anticoagulant agents for the treatment of both atrial fibrillation and venous thromboembolism even in very elderly patients. However, given the limited data available on the management of anticoagulation in nonagenarians, a few unanswered questions remain. In this review, we focused on recent evidence for anticoagulant treatment in atrial fibrillation and venous thromboembolism along with management of anticoagulation-related bleeding in nonagenarians.
\end{abstract}

\section{Introduction}

By 2040, it has been estimated that global life expectancy will increase by 4.4 years for men and 4.4 years for women, to 74.3 and 79.7 years, respectively. ${ }^{1}$ In most high-income countries, metabolic risk factors such as high blood pressure, high plasma fasting glucose, high body mass index, and tobacco will significantly increase. ${ }^{1}$ In the coming years, ischemic heart disease and stroke will remain among the leading causes of death in high-income countries. With this in mind, as life expectancy increases and health improves, it is important to assess optimal antithrombotic treatment in elderly populations. For patients aged 90 years and greater, the balance between anticoagulant-related bleeding and potential benefit of avoiding thrombotic events may be challenging to assess. This balance is particularly difficult to calculate since patients aged 90 years or older are often excluded from clinical trials and few data are available on current anticoagulant management and outcomes in this unique population. This review received

February 2, 2020

accepted after revision

May 7, 2020 (c) 2020 Georg Thieme Verlag KG Stuttgart · New York
DOI https://doi.org/

10.1055/a-1174-1290.

ISSN 0720-9355. 
focuses on evidence for anticoagulant treatment in atrial fibrillation (AF) and venous thromboembolism (VTE) along with management of anticoagulation-related bleeding in nonagenarians.

\section{Atrial Fibrillation}

$\mathrm{AF}$ is the most common heart rhythm disorder in daily practice. ${ }^{2}$ Its prevalence is strongly associated with increasing age and varies from $0.1 \%$ among persons younger than 55 years to $9.0 \%$ among patients 80 years or older. ${ }^{3}$ Given an aging global population, the burden of AF is growing. However, evidence on the efficacy and safety of antithrombotic therapies in patients aged 90 years or older from randomized or cohort studies is scarce. Thus, there is broad uncertainty concerning the overall clinical benefit of anticoagulation versus no anticoagulation as well as the best antithrombotic strategy in elderly AF patients.

\section{Antithrombotic Treatment in Nonagenarians}

It is well known that thromboembolic prevention management is often inadequate and de-prescribing in the elderly is common. Both physicians and patients contribute to deprescribing anticoagulation, patients because of the perceived risk of bleeding and the regular need for laboratory visits while physicians for the overestimation and fear of the risk of bleeding. ${ }^{4}$ Thus, some physicians are too aggressive on prescribing standard anticoagulation and others physicians tend to undertreat elderly patients, regardless of their general condition. This is of particular relevance in the frail elderly.

The critical dilemma is whether, in these older patients, the bleeding risks outweigh the expected benefits. This assessment is particularly challenging because many risk factors for bleeding are also risk factors for ischemic events. In the BAFTA randomized study, which included 973 patients with $A F$ aged $\geq 75$ years, the use of warfarin was associated with significant reduction of thromboembolic events (1.8 vs. 3.8\%/year, relative risk [RR]: $0.48 ; 95 \%$ confidence interval [CI]: $0.28-0.80$ ) without an increased risk of bleeding ( $1.9 \mathrm{vs.}$ 2.0\%/year, RR: 0.87; 95\% CI: 0.43-1.73) compared with antiplatelet therapy. ${ }^{5}$ However, it is not clear how many of these patients were aged $\geq 90$ years. Another analysis which included 366 patients with AF aged $\geq 85$ years treated with apixaban or aspirin from the AVERROES trial showed similar results. ${ }^{6}$ Fewer of these patients experienced stroke or systemic embolism when treated with apixaban versus aspirin (1.0 vs. $7.5 \%$, hazard ratio [HR]: $0.14 ; 95 \% \mathrm{CI}$ : $0.02-0.48$ ) with similar risk of major bleeding in the two groups (4.7 vs. $4.9 \%$ ). More recently, a sub-analysis of the observational PREFER registry in AF showed that the use of oral anticoagulation in patients aged $\geq 90$ years is associated with a reduction in thromboembolic events (odd ratio [OR]: $0.57 ; 95 \% \mathrm{CI}: 0.12-2.74 ; p=0.48$ ) and with a similar risk of bleedings (OR: $1.05 ; 95 \% \mathrm{CI}: 0.30-3.68 ; p=0.75$ ) compared with no antithrombotic treatment or antiplatelet therapy. ${ }^{7}$ In an effort to combine the overall risk of bleeding and thrombotic events, a decision analysis study using the char- acteristics of 14,946 patients aged 75 years or older with AF found that the net clinical benefit of anticoagulation decreased with age, providing a minimal benefit after age 87 years with warfarin and 92 years with apixaban. ${ }^{8}$ This study is the first to report that when all other health conditions affecting older adults are taken into account, the anticoagulant benefit actually decreases with age. Furthermore, the results confirm the importance of considering the competing risk of death in estimating the net clinical benefit of anticoagulant therapy particularly in the elderly population. While recognizing that under-treatment is a major concern in old age, this study now adds caution to our treatment decisions on anticoagulation in very elderly patients. Results of anticoagulant trials are summarized in - Table 1.

\section{Warfarin and Direct Oral Anticoagulants}

For several decades, vitaminK antagonists (VKAs) have been the anticoagulant of choice in AF. However, the need for monitoring and dose adjustment, polypharmacy, and comorbidities often lead to VKA nonadherence. The development of direct oral anticoagulants (DOACs) has dramatically changed oral anticoagulant treatment in AF. In AF patients, DOACs were shown to be noninferior to VKAs for the prevention of stroke or systemic embolism with the advantage of a 30 to $70 \%$ reduction in intracranial hemorrhage. ${ }^{9-12}$ Moreover, the predictable effect without the need for monitoring, fewer food and drug interactions, and shorter plasma half-life of DOACs may improve the efficacy/safety ratio in elderly patients.

Limited evidence is currently available on efficacy and safety of DOACs in elderly AF patients, especially in nonagenarians. In recent randomized AF phase III trials, the percentage of patients aged 75 years or older ranged from 12.8 to $43.2 \%$ and the mean age varies from 69.0 to 71.2 years. ${ }^{9-12}$ In the ARISTOTLE trial comparing apixaban to VKA, only $84(0.5 \%)$ of 18,201 were age $\geq 90$, while in the RE-LY study comparing dabigatran to VKA, only $79(0.4 \%)$ were aged $\geq 90$ years. ${ }^{9,10}$ In a recent meta-analysis of randomized clinical trials including patients aged 75 or older with AF and/or VTE, the risk of major or clinically relevant bleeding was not significantly different between DOACs and conventional therapy (OR: 1.02; 95\% CI: 0.73-$1.43) .^{13}$ In elderly population with AF, DOACs were more effective than conventional therapy (OR: $0.65 ; 95 \% \mathrm{CI}$ : $0.48-0.87$ ) in the prevention of stroke or systemic embolism. Among DOACs, only a reduced dose of apixaban and both doses (60 and $30 \mathrm{mg}$ ) of edoxaban were associated with lower major bleeding rates compared with VKAs in patients aged 75 years or older (OR: $0.63,95 \% \mathrm{CI}$ : $0.51-0.77$ apixaban; OR: 0.81, 95\% CI: 0.67-0.98 edoxaban $60 \mathrm{mg}$, OR: $0.46,95 \%$ CI: $0.38-0.57$ edoxaban $30 \mathrm{mg}$ ). Similar rates of major bleeding were observed for rivaroxaban or dabigatran in patients aged 75 years or older compared with VKAs (OR: $1.04,95 \%$ CI: 0.86-1.26 rivaroxaban; OR: $1.18,95 \% \mathrm{CI}$ : 0.97-1.44 dabigatran $150 \mathrm{mg}$, OR: $1.03,95 \%$ CI: 0.83-1.27 dabigatran $110 \mathrm{mg}$ ). Although dabigatran seemed to reduce intracranial bleedings compared with VKAs in the RE-LY 
Table 1 Main clinical features and outcomes of AF anticoagulant studies

\begin{tabular}{|c|c|c|c|c|c|c|c|}
\hline Study & Study design & $\begin{array}{l}\text { No. of } \\
\text { patients }\end{array}$ & $\begin{array}{l}\text { Mean } \\
\text { age } \\
\text { (y) }\end{array}$ & Treatment & $\begin{array}{l}\text { Mean } \\
\text { follow-up } \\
\text { (y) }\end{array}$ & $\begin{array}{l}\text { Efficacy } \\
\% \text { pts/y }\end{array}$ & $\begin{array}{l}\text { Safety } \\
\% \text { pts/y }\end{array}$ \\
\hline \multicolumn{8}{|c|}{ Anticoagulants vs.antiplatelets or placebo } \\
\hline BAFTA $^{4}$ & Randomized & $\begin{array}{l}485 \\
488\end{array}$ & $\begin{array}{l}81.5 \\
81.5\end{array}$ & $\begin{array}{l}\text { Antiplatelets } \\
\text { Warfarin }\end{array}$ & 2.7 & $\begin{array}{l}1.8 \% \\
3.8 \%\end{array}$ & $\begin{array}{l}1.9 \% \\
2.0 \%\end{array}$ \\
\hline AVERROES 5 & Randomized & 366 & $\geq 85$ & $\begin{array}{l}\text { Aspirin } \\
\text { Apixaban }\end{array}$ & 1 & $\begin{array}{l}7.5 \% \\
1.0 \%\end{array}$ & $\begin{array}{l}4.7 \% \\
4.9 \%\end{array}$ \\
\hline PREFER AF & $\begin{array}{l}\text { Observational } \\
\text { (prospective) }\end{array}$ & $\begin{array}{l}58 \\
26\end{array}$ & $\geq 90$ & $\begin{array}{l}\text { Anticoagulation } \\
\text { Placebo/antiplatelets }\end{array}$ & 1 & $\begin{array}{l}6.9 \% \\
11.5 \%\end{array}$ & $\begin{array}{l}8.6 \% \\
7.7 \%\end{array}$ \\
\hline \multicolumn{8}{|c|}{ Warfarin vs.direct oral anticoagulants } \\
\hline ARISTOTLE $^{8}$ & Randomized & $\begin{array}{l}2,850 \\
2,828\end{array}$ & $\geq 75$ & $\begin{array}{l}\text { Apixaban } \\
\text { Warfarin }\end{array}$ & 1.8 & $\begin{array}{l}1.6 \% \\
2.2 \%\end{array}$ & $\begin{array}{l}3.3 \% \\
5.2 \%\end{array}$ \\
\hline RE-LY ${ }^{9}$ & Randomized & $\begin{array}{l}4,815 \\
2,423\end{array}$ & $\geq 75$ & $\begin{array}{l}\text { Dabigatran } \\
\text { Warfarin }\end{array}$ & 2 & $\begin{array}{l}1.4 \%(\mathrm{~d} 150) \\
1.9 \%(\mathrm{~d} 110) \\
2.1 \% \text { (warfarin) }\end{array}$ & $\begin{array}{l}.1 \%(\mathrm{~d} 150) \\
4.4 \%(\mathrm{~d} 110) \\
4.4 \% \text { (warfarin) }\end{array}$ \\
\hline ROCKET-AF ${ }^{10}$ & Randomized & $\begin{array}{l}3,082 \\
3,082 \\
\end{array}$ & $\geq 75$ & $\begin{array}{l}\text { Rivaroxaban } \\
\text { Warfarin }\end{array}$ & 2 & $\begin{array}{l}4.1 \% \\
5.0 \% \\
\end{array}$ & $\begin{array}{l}25.8 \% \\
23.4 \% \\
\end{array}$ \\
\hline ENGAGE $\mathrm{AF}^{11}$ & Randomized & $\begin{array}{l}5,654 \\
2,820\end{array}$ & $\geq 75$ & $\begin{array}{l}\text { Edoxaban } \\
\text { Warfarin }\end{array}$ & 2.8 & $\begin{array}{l}1.9 \% \\
2.3 \%\end{array}$ & $\begin{array}{l}4.0 \% \\
4.8 \%\end{array}$ \\
\hline $\begin{array}{l}\text { Giustozzi } \\
\text { et al }{ }^{15}\end{array}$ & $\begin{array}{l}\text { Observational } \\
\text { (retro and } \\
\text { prospective) }\end{array}$ & $\begin{array}{l}245 \\
301\end{array}$ & $\begin{array}{l}92 \\
92\end{array}$ & $\begin{array}{l}\text { DOACs } \\
\text { Warfarin }\end{array}$ & 1.2 & $\begin{array}{l}2.4 \% \\
2.3 \%\end{array}$ & $\begin{array}{l}6.3 \% \\
4.2 \%\end{array}$ \\
\hline Chao et al ${ }^{16}$ & $\begin{array}{l}\text { Observational } \\
\text { (retrospective) }\end{array}$ & $\begin{array}{l}978 \\
768\end{array}$ & $\begin{array}{l}93 \\
93\end{array}$ & $\begin{array}{l}\text { DOACs } \\
\text { Warfarin }\end{array}$ & 2.1 & $\begin{array}{l}4.1 \% \\
4.6 \%\end{array}$ & $\begin{array}{l}6.1 \% \\
6.8 \%\end{array}$ \\
\hline
\end{tabular}

Abbreviation: AF, atrial fibrillation.

trial, it also seemed to raise the incidence of major extracranial bleeding in the elderly. Moreover, although only limited elderly people are represented in phase III clinical trials investigating DOACs, a recent European consensus from 2015 recommends the use of oral factor Xa (FXa) inhibitors over VKAs in the elderly with nonvalvular AF if creatinine clearance $>15 \mathrm{~mL} / \mathrm{min}$, given the lower incidence of intracranial hemorrhage, the favorable overall efficacy and safety, and the lack of routine monitoring. ${ }^{14}$

In a prospective cohort of study of $245 \mathrm{AF}$ patients aged 90 years or older on DOACs, the rate of ischemic stroke or transient ischemic attack was $2.4 \%$ patient-year and that of major bleeding was $6.8 \%$ patient-year (-Table 1 ). ${ }^{15}$ No differences were observed in terms of risk of ischemic stroke and major bleeding between DOACs and VKAs, although one limitation of the study was the different data collection (301 VKA retrospective cohort and 245 DOAC prospective cohort). Recently, in a retrospective study of 1,750 nonagenarians with AF, DOACs were associated with a lower risk of death and embolic events and aninsignificant increased risk of major bleeding compared to non-anticoagulation ( - Table 1). ${ }^{16}$ Finally, there is little evidence on the safety and efficacy of new treatment options for AF such as left atrial appendage occlusion or AF ablation in elderly patients. In a retrospective study of 75 patients with AF aged 80 or older, left atrial appendage occlusion appeared to be a safe and effective option for stroke prevention. ${ }^{17}$ Similarly, in 84 patients aged 85 years or older, there were no differences in 7-day device- or procedure-related adverse event rates or in annualized stroke rates between patients aged $\geq 85$ years and $<85$ years. ${ }^{18}$

In conclusion, there is a broad range of interest in the best treatment for AF in patients aged 90 years or older. However, clinical trials should include more nonagenarians to yield more robust evidence in this issue.

\section{Open Questions and Future Perspectives}

Given the lack of robust evidence, there are still several open questions about AF in nonagenarian patients. First, the real net clinical benefit of antithrombotic therapy still remains to be defined in these patients. Further large-scale epidemiological studies taking into account the competing risk of death are needed. Second, further investigations are needed to understand who is the frail elderly patient who may benefit or not from anticoagulant therapy. In this perspective, anticoagulation should be tailored to certain clinical issues that often coexist in nonagenarians, such as multiple comorbidities, concomitant drugs, risk of falls, cognitive deterioration, and reduction of life expectancy (-Fig. 1). Third, it is important to answer the question of what is the optimal antithrombotic treatment that can be used safely even at an older age. Indeed, further studies, possibly randomized, are required to evaluate the safety and efficacy of DOACs or warfarin in nonagenarians with AF. Given the worldwide growth of the oldest age patients, especially those aged over 90 years, there is a need to improve knowledge to prevent and to cure AF in nonagenarians. 


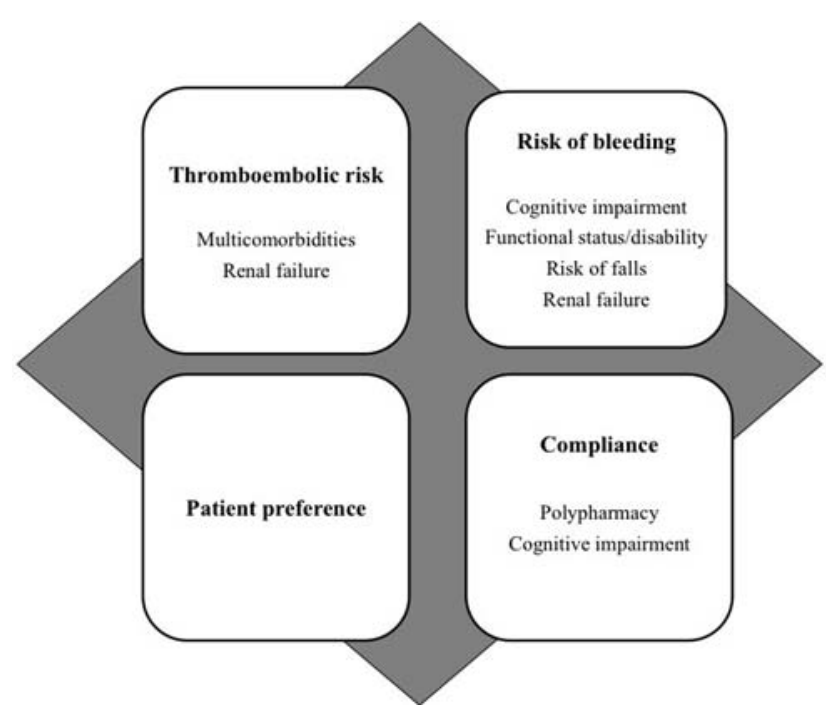

Fig. 1 Management of atrial fibrillation in nonagenarians.

\section{Venous Thromboembolism}

Venous Thromboembolism Incidence and Risk Factors VTE, defined as pulmonary embolism (PE) and deep vein thrombosis (DVT), is a common disease, rising exponentially with age. ${ }^{19}$ The incidence of acute VTE in individuals $<50$ years is $<1$ case per 1,000 person-years compared with 6 to 8 cases per 1,000 person-years in those $>80$ years, depending on ethnicity. ${ }^{20,21}$ Several risk factors are more prevalent to the elderly population, including comorbidities of cancer, coronary disease, congestive heart failure, chronic obstructive pulmonary disease, stroke, obesity, diabetes, frailty, immobilization, hospitalizations, and prior VTE, among others. In general, elderly patients with multiple risk factors have a greater risk of first VTE compared with younger populations. ${ }^{19,22,23}$ While the aged population will result in a rising VTE incidence, the overall case-fatality rate is not rising, likely owing to more effective interventions and therapies. ${ }^{24}$ However, little information is known on VTE management and risk of recurrence in the nonagenarian population.

\section{Diagnostic Imaging for VTE in Nonagenarians}

Compression ultrasonography of the proximal veins or whole leg for distal veins is the standard diagnostic modality used to evaluate suspected DVT. The sensitivity and specificity of this technique do not vary according to patient's age. ${ }^{25}$ For suspected PE, the diagnostic accuracy of computed tomography pulmonary angiography (CTPA) is also not age-dependent, and CTPA is the preferred imaging technique used for PE given its widespread availability. ${ }^{26}$ Limitations to use of CTPA include contrast dye allergy and risk of contrast-induced acute kidney injury in those with pre-existing renal impairment. ${ }^{27} \mathrm{~A}$ potentially useful diagnostic imaging tool in patients with suspected $\mathrm{PE}$ and renal disease is ventilation-perfusion $(\mathrm{V} / \mathrm{Q})$ scan. Users need to be cognizant that the probability of inconclusive or intermediate-probability V/Q scans increases with age, often necessitating additional investigations. ${ }^{28}$

\section{Treatment of VTE in Nonagenarians}

Although the risk of VTE increases with age, there are limited data on the safest and most effective anticoagulation therapy in nonagenarians. DOACs are first-line therapy in VTE treatment in patients without cancer, owing to their favorable bleeding profile, in particular reduced intracranial bleedings. ${ }^{29-31}$ The efficacy and safety of DOACs have not been specifically evaluated in older patients in phase 3 trials, with only $14 \%$ of participants in VTE DOAC trials aged $>75$ years; no information is reported for participants $>90$ years. Subgroup analyses of patients $>75$ years demonstrated excellent efficacy and safety profiles of DOACs compared with VKA (RR: 0.56; 95\% CI: $0.38-0.82$ and RR: $0.49 ; 95 \% \mathrm{CI}: 0.25-0.96$, respectively). ${ }^{32}$ These data reinforce the superior reduction in recurrent VTE of DOACs to VKAs without compromising bleeding risks in elderly patients with acute VTE.

\section{Recurrent VTE and Extended Treatment}

The risk of recurrent VTE is an important consideration for the length of anticoagulation treatment. In patients with provoked acute VTE, a short duration of 3 months of anticoagulation treatment is sufficient. ${ }^{29}$ However, patients with unprovoked index VTE have a greater risk for recurrent thrombosis, potentially warranting extended anticoagulation. Several clinical risk prediction models for recurrent VTE in patients with first unprovoked VTE exist, including Men Continue and HERDOO2, the DASH score, and the Vienna Prediction Model. ${ }^{33-35}$ Limitations of their application to nonagenarians when determining those at low risk for recurrent VTE and whocan safely stop anticoagulation include nonapplicability to all-comers $>65$ years, invalidity in the elderly population, and lack of discriminant power in elderly patients. A multicenter prospective cohort study in Switzerland, the SWIss venous ThromboembolismCOhort $($ SWITCO65 + ), evaluated 991 acute VTE patients aged $>65$ years for predictors and outcomes of recurrent VTE. ${ }^{36}$ Variables previously identified to be associated with recurrent VTE were collected, including baseline patient demographics (age, male gender, obesity), index VTE (PE, proximal DVT, distal DVT), provoked or unprovoked nature of index event, prior VTE, and medical comorbidities, among others. The association between these variables and risk of recurrent VTE was evaluated using a competing risk regression (for non-VTE-related deaths). The median age of participants was 75 years and the cumulative incidence of recurrent VTE at 3 years was $15 \%$. Over a follow-up period of 36 months, the only risk factors associated with recurrent VTE were proximal DVT (adjusted HR: 2.41; 95\% CI: 1.07-5.38, compared with distal DVT) and unprovoked VTE (adjusted HR: 1.67; 95\% CI: 1.00-2.77, compared with provoked VTE). Importantly, these findings highlight that typical risk factors previously identified to increase risk of recurrent VTE may not be relevant to patients older than 75 years. Additional risk stratification studies are needed for elderly patients. With respect to outcomes in this cohort of elderly patients with recurrent VTE, $20 \%$ of recurrences were fatal, and the highest was in those with index PE (23\%) and those with cancer-associated VTE (29\%). ${ }^{36}$ 
Determining the risk of recurrent VTE and the decision to extend anticoagulation treatment is no different in nonagenarians than in a younger population in that a consideration of bleeding risk must be included. The exclusion of many elderly patients in phase 3 VTE DOAC trials was due to the presence of increased bleeding risk. ${ }^{37}$ The American College of Chest Physicians (ACCP) 2016 VTE guidelines suggested a bleeding risk model that deemed patients older than 75 years at high risk for bleeding. As such, patients aged 75 and older should receive anticoagulation treatment for a minimum of 3 months following unprovoked VTE, after which balancing risks of recurrent VTE and bleeding should guide the decision to extend anticoagulation. ${ }^{28}$ Incorporation of patient preferences should also be considered. As with clinical prediction models to determine recurrent VTE risk, there are inaccuracies when applying bleeding risk models in the elderly. Additional information on bleeding risk and bleeding management can be found below.

\section{Open Questions and Future Perspectives}

There are unanswered questions regarding VTE management in nonagenarians due to their under-representation in phase 3 clinical trials. Future research should aim to evaluate efficacy and safety of different anticoagulants in elderly patients. Additional consideration would include the duration of anticoagulation. In support of this decision on treatment duration, clinical prediction models for recurrent VTE and bleeding risk derived from and validated in an elderly population are needed.

\section{Managing Anticoagulation-Related Bleeding in Nonagenarians}

\section{Bleeding Risk in Elderly Patients}

Bleeding is a common side effect of anticoagulant medication use. This is particularly true for elderly patients. ${ }^{38}$ In fact, most bleeding risk assessment models include age as a predictor. For example, the HAS-BLED score gives one point for age $\geq 65$ years. ${ }^{39}$ The ATRIA, ORBIT, and HEMORRHAGES scores each give points for age $\geq 75 .{ }^{40-42}$ Recognizing that the association between age and bleeding risk is likely not binary, the $A B C$ score assigns bleeding risk along the continuum of age between 44 and 90 years. ${ }^{43}$ Yet little data are available to accurately predict risk of bleeding in nonagenarians. In fact, use of bleeding risk scores derived from younger patients may underestimate the risk of bleeding in the most elderly patients. ${ }^{44,45}$ And even less data are available to guide nonagenarians in assessing bleeding risk between various oral anticoagulant medications. ${ }^{46}$

Anticoagulation-related bleeding varies widely in severity. The majority of bleeding events are not life-threatening but can cause significant concern or distress to patients. ${ }^{47}$ These include prolonged bleeding after a skin laceration, frequent bruising, and epistaxis. However, severe bleeding can often be life-threatening, especially for the most elderly patients. And up to one-third of patients do not restart their anticoagulant following a bleeding event. ${ }^{47-49}$ Therefore, strategies to prevent bleeding are critical to ensure ongoing thromboembolism prevention with anticoagulation therapy. Importantly, patients are less likely to experience bleeding complications when they are taking fewer antithrombotic agents, using gastroprotection, and increasing physical activity. ${ }^{50-52}$

\section{Managing Anticoagulation-Related Bleeding}

The management of patients with anticoagulation-related bleeding should be similar regardless of age ( - Table 2 ). The recent 2017 American College of Cardiology Expert Consensus Document outlines three key steps in anticoagulantrelated bleeding management. ${ }^{53}$

\section{Step 1: Assess the Severity of Bleeding}

A life-threatening bleeding event is typically one that occurs in a critical organ and results in hemodynamic instability. Nonagenarians may be at particular risk of bleeding-related hemodynamic instability, particularly if they have comorbid conditions that limit their cardiopulmonary reserve. These patients require urgent intervention to prevent further decompensation and/or permanent injury.

Patients experiencing anticoagulation-related bleeding in a noncritical site (e.g., gastrointestinal track) that does not result in hemodynamic instability may still be at risk for poor outcomes. In particular, patients who present with a significant drop in hemoglobin (usually $\geq 2 \mathrm{~g} / \mathrm{dL}$ ) or require significant blood product transfusions ( $\geq 2$ units of packed red blood cells) are at increased risk for complications, including death. Collectively, these are referred to as major bleeding events. Prompt response to control bleeding and stabilize the patient is warranted in these situations as well.

Patients with active bleeding that does not meet the above criteria are considered to have nonmajor bleeding events. When the bleeding results in contact with the health care system (e.g., clinic or emergency department visit), they are considered clinically relevant nonmajor bleeding. ${ }^{54}$

\section{Step 2: Manage and Control Bleeding}

For all patients with clinically relevant nonmajor, major, or life-threatening bleeding, the first step in management is to hold further anticoagulant administration. Patients with nuisance bleeding (e.g., minor cuts and bruises) can often continue taking their anticoagulants uninterrupted. Consideration should be made to mitigate any procedurerelated risk from these local measures in nonagenarians, especially if their baseline cardiopulmonary reserve is limited.

For patients with life-threatening bleeding or for whom the local measures are unable to control the bleeding source, reversal of anticoagulation may be appropriate. Laboratory testing should be conducted to verify the degree of active anticoagulation.

For warfarin-related bleeding events, use of 4 -factor prothrombin concentrate complex (PCC) is preferred over fresh frozen plasma. In addition to its quicker administration, 
Table 2 Management of anticoagulant-related bleeding in nonagenarians

\begin{tabular}{|c|c|c|}
\hline Step & Key points & Considerations for nonagenarians \\
\hline \multirow[t]{3}{*}{ 1. Assess severity } & $\begin{array}{l}\text { Life-threatening } \\
\text { - Critical organ OR } \\
\text { - Hemodynamic instability }\end{array}$ & \multirow[t]{3}{*}{$\begin{array}{l}\text { - Comorbidities may increase risk for } \\
\text { hemodynamic instability }\end{array}$} \\
\hline & $\begin{array}{l}\text { Major } \\
\text { - Noncritical organ } \\
\text { - Hemodynamically stable } \\
\text { - } 2+\mathrm{g} / \mathrm{dL} \text { hemoglobin drop OR } 2+\text { unit } \\
\text { red blood cell transfusion }\end{array}$ & \\
\hline & $\begin{array}{l}\text { Nonmajor } \\
\text { - Require health system contact } \\
\text { - Little or no hemoglobin drop or } \\
\text { transfusion requirement }\end{array}$ & \\
\hline $\begin{array}{l}\text { 2. Manage and } \\
\text { control bleeding }\end{array}$ & $\begin{array}{l}\text { - Hold anticoagulant unless nuisance bleed } \\
\text { - Initiate local control measures } \\
\text { - Consider reversal if life-threatening bleed } \\
\text { - Warfarin } \rightarrow 4 \mathrm{~F}-\mathrm{PCC} \\
\text { - Dabigatran } \rightarrow \text { idarucizumab } \\
\text { - Factor Xa inhibitors } \rightarrow \text { 4F-PCC } \\
\quad \text { or andexanet } \alpha\end{array}$ & $\begin{array}{l}\text { - Consider procedural risk if patient has impaired } \\
\text { cardiopulmonary status } \\
\text { - Avoid high-volume reversal with FFP whenever possible }\end{array}$ \\
\hline $\begin{array}{l}\text { 3. Restart } \\
\text { anticoagulant }\end{array}$ & $\begin{array}{l}\text { - Re-assess thrombotic risk } \\
\text { - Determine timing for restart } \\
-1 \text { wk for most gastrointestinal bleeds } \\
-4-8 \text { wk for intracranial hemorrhage }\end{array}$ & $\begin{array}{l}\text { - Often at very high thromboembolic risk } \\
\text { - Restarting anticoagulant is usually recommended }\end{array}$ \\
\hline
\end{tabular}

Abbreviations: 4F-PCC, 4-factor prothrombin complex concentrate; FFP, fresh frozen plasma.

it also requires significantly less volume to administer than fresh frozen plasma. For nonagenarians who may have comorbid cardiac conditions, avoiding excess volume may help to prevent pulmonary edema and other issues related to congestive heart failure.

For patients with dabigatran-related bleeding events, use of idarucizumab $5 \mathrm{~g}$ intravenous bolus is recommended for major and life-threatening bleeding events. If idarucizumab is not available, then 4-factor PCC or activated PCC would be recommended. The REVERSE-AD study of dabigatran-related reversal with idarucizumab included patients up to 93 years of age and therefore would be applicable to nonagenarians. ${ }^{55}$

For patients with FXa inhibitor-related bleeding events, use of 4-factor PCC is recommended for most major and lifethreatening bleeding events. In some circumstances, patients with apixaban- or rivaroxaban-related life-threatening bleeding (e.g., intracranial) may be treated with andexanet $\alpha$ bolus followed by 2-hour infusion. However, availability of andexanet $\alpha$ is currently quite limited and has significant cost implications. Dosing is based on specific anticoagulant, dose, and time since last anticoagulant administration. The ANNEXA-4 study of apixaban and rivaroxaban reversal with andexanet $\alpha$ included an older population (mean \pm standard deviation: $77 \pm 10$ years), which did not directly specify including nonagenarian patients. ${ }^{56}$

\section{Step 3: Restarting Anticoagulants}

The final, and perhaps most consequential, step in managing anticoagulation-related bleeding is determining if and when the anticoagulant should be restarted. As with any medicationrelated adverse event, this is a prime opportunity to re-evaluate the necessity of anticoagulation therapy.

Nonagenarian patients are often at high thromboembolic risk. If the ongoing risk of bleeding can be mitigated, then the risk-benefit balance often favors re-initiation. ${ }^{57-59}$ Typically, only 1 week is necessary for patients with gastrointestinal bleeding that has been intervened. ${ }^{49}$ Other patients such as those with intracranial hematoma or traumatic bleeding may benefit from anticoagulationfree periods of up to 4 to 8 weeks from the event. ${ }^{48,57,59}$ However, these data are largely extrapolated from slightly younger populations as minimal data in nonagenarians are published.

\section{Open Questions}

Given the limited published data on anticoagulation-related bleeding in nonagenarians, a few key questions remain. These can be framed in terms of the three steps of anticoagulation-related bleeding management. First, it is unclear if definitions of life-threatening, major, and nonmajor bleeding result in similar risks of death among nonagenarian and younger patients experiencing anticoagulation-related bleeding. Second, while the use of various anticoagulation reversal strategies has been studied, safety and efficacy data are largely lacking in nonagenarian patients. And third, how ongoing risks of thromboembolism versus anticoagulationrelated bleeding are calculated and compared in nonagenarian patients is largely unreported. Given the aging population and increasing use of oral anticoagulants, especially 
DOACs, these questions remain high in priority to inform clinical care.

\section{Conclusions}

Given the growth of older patients worldwide, especially those over 90 years of age, there is a need to improve knowledge about the management of anticoagulant treatment and anticoagulation-related complications in nonagenarians. Therefore, clinical studies should include more nonagenarians in the coming years to produce more robust evidence for this issue.

\section{Time Capsule}

- In the next 30 years, almost all patients with AF aged 90 years or older will receive oral anticoagulant treatment. Factors Xa inhibitors (or a new class of antithrombotic agents) will be the anticoagulants of choice, while warfarin and aspirin will no longer be used in this setting. Left atrial appendage occlusion will become a valid option in elderly AF patients where anticoagulation is contraindicated.

- In 2050, a lowdose of direct oral anticoagulants will be the treatment of choice for acute VTE in nonagenarians.

- In the next 30 years, evidence supporting safe use of anticoagulant-specific reversal strategies will support these approaches, even if newer antithrombotic agents are eventually introduced.

\section{Conflict of Interest}

The authors declare that they have no conflict of interest.

\section{Authors}

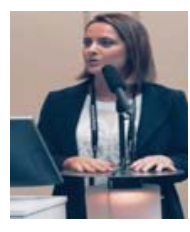

\section{Michela Giustozzi}

Dr. Giustozzi's clinical activity is mainly focused on the management and treatment of cardiovascular disease while her research studies mainly investigate thromboembolic disease, both at venous and arterial site. Other areas of interest also include antithrombotic therapy and atrial fibrillation.

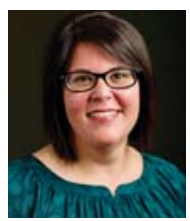

\section{Lana Castellucci}

Lana Castellucci, MD, FRCPC, MSc, is an Assistant Professor in the Faculty of Medicine at the University of Ottawa, and an Associate Scientist at The Ottawa Hospital Research Institute. She sits on the Board of Directors of Thrombosis Canada, a national organization promoting patient education and improved outcomes for patients with venous thrombosis. She is an active member of the CanVECTOR (Canadian Venous Thromboembolism Clinical Trials and Outcomes Research) Network, and recipient of the Heart and Stroke Foundation of Canada National New Investigator Award.
Dr. Castellucci's clinical and research interests are focused on the prevention, diagnosis and management of anticoagulantrelated bleeding and venous thromboembolism. She is the Principal Investigator of a peer-reviewed international clinical trial (funded by the Canadian Institutes of Health Research) Comparison of Bleeding Risk between Rivaroxaban and Apixaban (COBRRA) in patients with acute venous thromboembolism. She completed her Thrombosis fellowship at the University of Ottawa under the mentorship of Drs. Carrier, Le Gal, Rodger, and Wells.

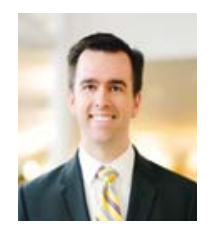

\section{Geoffrey Barnes}

Geoffrey Barnes, MD, MSc, is a cardiologist and vascular medicine specialist at the University of Michigan Frankel Cardiovascular Center. His clinical practice involves care of patients on chronic anticoagulant medications or with thrombotic disorders. He is a health services researcher with expertise in the implementation and evaluation of anticoagulation management strategies. In addition to research funding from the NIH and AHRQ, he serves as co-director of the Michigan Anticoagulation Quality Improvement Initiative (MAQI2). He completed his medical school, residency, and fellowship training at the University of Michigan under the mentorship of Drs. Jim Froehlich and Anne Sales.

\section{References}

1 Foreman KJ, Marquez N, Dolgert A, et al. Forecasting life expectancy, years of life lost, and all-cause and cause-specific mortality for 250 causes of death: reference and alternative scenarios for 2016-40 for 195 countries and territories. Lancet 2018;392 (10159):2052-2090

2 Kirchhof P, Benussi S, Kotecha D, et al. 2016 ESC Guidelines for the management of atrial fibrillation developed in collaboration with EACTS. Europace 2016;18(11):1609-1678

3 Go AS, Hylek EM, Phillips KA, et al. Prevalence of diagnosed atrial fibrillation in adults: national implications for rhythm management and stroke prevention: the AnTicoagulation and Risk Factors in Atrial Fibrillation (ATRIA) Study. JAMA 2001;285(18):2370-2375

4 O'Mahony D, Gallagher PF. Inappropriate prescribing in the older population: need for new criteria. Age Ageing 2008;37(02): 138-141

5 Mant J, Hobbs FD, Fletcher K, et al; BAFTA Investigators; Midland Research Practices Network (MidReC). Warfarin versus aspirin for stroke prevention in an elderly community population with atrial fibrillation (the Birmingham Atrial Fibrillation Treatment of the Aged Study, BAFTA): a randomised controlled trial. Lancet 2007; 370(9586):493-503

6 Connolly SJ, Eikelboom J, Joyner C, et al; AVERROES Steering Committee and Investigators. Apixaban in patients with atrial fibrillation. N Engl J Med 2011;364(09):806-817

7 Patti G, Lucerna M, Pecen L, et al. Thromboembolic risk, bleeding outcomes and effect of different antithrombotic strategies in very elderly patients with atrial fibrillation: a sub-analysis from the PREFER in AF (PREvention oF Thromboembolic Events-European Registry in Atrial Fibrillation). J Am Heart Assoc 2017;6(07): e005657

8 Shah SJ, Singer DE, Fang MC, Reynolds K, Go AS, Eckman MH. Net clinical benefit of oral anticoagulation among older adults with atrial fibrillation. Circ Cardiovasc Qual Outcomes 2019;12(11): e006212 
9 Granger CB, Alexander JH, McMurray JJ, et al; ARISTOTLE Committees and Investigators. Apixaban versus warfarin in patients with atrial fibrillation. N Engl J Med 2011;365(11):981-992

10 Connolly SJ, Ezekowitz MD, Yusuf S, et al; RE-LY Steering Committee and Investigators. Dabigatran versus warfarin in patients with atrial fibrillation. N Engl J Med 2009;361(12):1139-1151

11 Patel MR, Mahaffey KW, Garg J, et al; ROCKET AF Investigators. Rivaroxaban versus warfarin in nonvalvular atrial fibrillation. N Engl J Med 2011;365(10):883-891

12 Giugliano RP, Ruff CT, Braunwald E, et al; ENGAGE AF-TIMI 48 Investigators. Edoxaban versus warfarin in patients with atrial fibrillation. N Engl J Med 2013;369(22):2093-2104

13 Sharma M, Cornelius VR, Patel JP, Davies JG, Molokhia M. Efficacy and harms of direct oral anticoagulants in the elderly for stroke prevention in atrial fibrillation and secondary prevention of venous thromboembolism: systematic review and meta-analysis. Circulation 2015;132(03):194-204

14 Andreotti F, Rocca B, Husted S, et al; ESC Thrombosis Working Group. Antithrombotic therapy in the elderly: expert position paper of the European Society of Cardiology Working Group on Thrombosis. Eur Heart J 2015;36(46):3238-3249

15 Giustozzi M, Vedovati MC, Verso M, et al. Patients aged 90 years or older with atrial fibrillation treated with oral anticoagulants: a multicentre observational study. Int J Cardiol 2019;281:56-61

16 Chao TF, Liu CJ, Lin YJ, et al. Oral anticoagulation in very elderly patients with atrial fibrillation: a nationwide cohort study. Circulation 2018;138(01):37-47

17 Gafoor S, Franke J, Bertog S, et al. Left atrial appendage occlusion in octogenarians: short-term and 1-year follow-up. Catheter Cardiovasc Interv 2014;83(05):805-810

18 Cruz-González I, Ince H, Kische S, et al. Left atrial appendage occlusion in patients older than 85 years. Safety and efficacy in the EWOLUTION registry. Rev Esp Cardiol (Engl Ed) 2020;73(01):21-27

19 Spencer FA, Gore JM, Lessard D, et al. Venous thromboembolism in the elderly. A community-based perspective. Thromb Haemost 2008;100(05):780-788

20 Tagalakis V, Patenaude V, Kahn SR, Suissa S. Incidence of and mortality from venous thromboembolism in a real-world population: the Q-VTE Study Cohort. Am J Med 2013;126(09):832. e13-832.e21

21 Raskob GE, Angchaisuksiri P, Blanco AN, et al; ISTH Steering Committee for World Thrombosis Day. Thrombosis: a major contributor to global disease burden. Semin Thromb Hemost 2014;40(07):724-735

22 Silverstein RL, Bauer KA, Cushman M, Esmon CT, Ershler WB, Tracy RP. Venous thrombosis in the elderly: more questions than answers. Blood 2007;110(09):3097-3101

23 Engbers MJ, van Hylckama Vlieg A, Rosendaal FR. Venous thrombosis in the elderly: incidence, risk factors and risk groups. J Thromb Haemost 2010;8(10):2105-2112

24 Konstantinides SV, Meyer G, Becattini C, et al; ESC Scientific Document Group. 2019 ESC Guidelines for the diagnosis and management of acute pulmonary embolism developed in collaboration with the European Respiratory Society (ERS). Eur Heart J 2020;41(04):543-603

25 Bates SM, Jaeschke R, Stevens SM, et al. Diagnosis of DVT: Antithrombotic Therapy and Prevention of Thrombosis, 9th ed: American College of Chest Physicians Evidence-Based Clinical Practice Guidelines. Chest 2012;141(2 Suppl):e351S-e418S

26 Righini M, Bounameaux H, Perrier A. Effect of age on the performance of single detector helical computed tomography in suspected pulmonary embolism. Thromb Haemost 2004;91(02): 296-299

27 Khwaja A. KDIGO clinical practice guidelines for acute kidney injury. Nephron Clin Pract 2012;120(04):c179-c184

28 Righini M, Goehring C, Bounameaux H, Perrier A. Effects of age on the performance of common diagnostic tests for pulmonary embolism. Am J Med 2000;109(05):357-361
29 Kearon C, Akl EA, Ornelas J, et al. Antithrombotic therapy for VTE disease: CHEST guideline and expert panel report. Chest 2016; 149(02):315-352

30 Castellucci LA, Cameron C, Le Gal G, et al. Clinical and safety outcomes associated with treatment of acute venous thromboembolism: a systematic review and meta-analysis. JAMA 2014; 312(11):1122-1135

31 Chai-Adisaksopha C, Crowther M, Isayama T, Lim W. The impact of bleeding complications in patients receiving target-specific oral anticoagulants: a systematic review and meta-analysis. Blood 2014;124(15):2450-2458

32 van Es N, Coppens M, Schulman S, Middeldorp S, Büller HR. Direct oral anticoagulants compared with vitamin $\mathrm{K}$ antagonists for acute venous thromboembolism: evidence from phase 3 trials. Blood 2014;124(12):1968-1975

33 Rodger MA, Le Gal G, Anderson DR, et al; REVERSE II Study Investigators. Validating the HERDOO2 rule to guide treatment duration for women with unprovoked venous thrombosis: multinational prospective cohort management study. BMJ 2017;356: j1065

34 Tosetto A, Iorio A, Marcucci M, et al. Predicting disease recurrence in patients with previous unprovoked venous thromboembolism: a proposed prediction score (DASH). J Thromb Haemost 2012;10 (06):1019-1025

35 Eichinger S, Heinze G, Kyrle PA. D-dimer levels over time and the risk of recurrent venous thromboembolism: an update of the Vienna prediction model. J Am Heart Assoc 2014;3(01): e000467

36 Lauber S, Limacher A, Tritschler T, et al. Predictors and outcomes of recurrent venous thromboembolism in elderly patients. Am J Med 2018;131(06):703.e7-703.e16

37 Tritschler T, Aujesky D. Venous thromboembolism in the elderly: a narrative review. Thromb Res 2017;155:140-147

38 Kooistra HA, Calf AH, Piersma-Wichers M, et al. Risk of bleeding and thrombosis in patients 70 years or older using vitamin $\mathrm{K}$ antagonists. JAMA Intern Med 2016;176(08):1176-1183

39 Pisters R, Lane DA, Nieuwlaat R, de Vos CB, Crijns HJ, Lip GY. A novel user-friendly score (HAS-BLED) to assess 1-year risk of major bleeding in patients with atrial fibrillation: the Euro Heart Survey. Chest 2010;138(05):1093-1100

40 Fang MC, Go AS, Chang Y, et al. A new risk scheme to predict warfarin-associated hemorrhage: the ATRIA (Anticoagulation and Risk Factors in Atrial Fibrillation) Study. J Am Coll Cardiol 2011;58 (04):395-401

41 O'Brien EC, Simon DN, Thomas LE, et al. The ORBIT bleeding score: a simple bedside score to assess bleeding risk in atrial fibrillation. Eur Heart J 2015;36(46):3258-3264

42 Gage BF, Yan Y, Milligan PE, et al. Clinical classification schemes for predicting hemorrhage: results from the National Registry of Atrial Fibrillation (NRAF). Am Heart J 2006;151(03):713-719

43 Hijazi Z, Oldgren J, Lindbäck J, et al; ARISTOTLE and RE-LY Investigators. The novel biomarker-based ABC (age, biomarkers, clinical history)-bleeding risk score for patients with atrial fibrillation: a derivation and validation study. Lancet 2016;387 (10035):2302-2311

44 Hylek EM, Evans-Molina C, Shea C, Henault LE, Regan S. Major hemorrhage and tolerability of warfarin in the first year of therapy among elderly patients with atrial fibrillation. Circulation 2007;115(21):2689-2696

45 Poli D, Antonucci E, Marcucci R, et al. Risk of bleeding in very old atrial fibrillation patients on warfarin: relationship with ageing and CHADS2 score. Thromb Res 2007;121(03):347-352

46 Peeterbroeck J, Danguy C, Lelubre C, Meulemans M, Higuet S. Bleeding complications with oral anticoagulants in the elderly: an observational study. Geriatr Psychol Neuropsychiatr Vieil 2016; 14(04):406-412

47 O'Brien EC, Holmes DN, Thomas L, et al. Therapeutic strategies following major, clinically relevant nonmajor, and nuisance 
bleeding in atrial fibrillation: findings from ORBIT-AF. J Am Heart Assoc 2018;7(12):e006391

48 Yung D, Kapral MK, Asllani E, Fang J, Lee DS; Investigators of the Registry of the Canadian Stroke Network. Reinitiation of anticoagulation after warfarin-associated intracranial hemorrhage and mortality risk: the Best Practice for Reinitiating Anticoagulation Therapy After Intracranial Bleeding (BRAIN) study. Can J Cardiol 2012;28(01):33-39

49 Qureshi W, Mittal C, Patsias I, et al. Restarting anticoagulation and outcomes after major gastrointestinal bleeding in atrial fibrillation. Am J Cardiol 2014;113(04):662-668

50 Hansen ML, Sørensen R, Clausen MT, et al. Risk of bleeding with single, dual, or triple therapy with warfarin, aspirin, and clopidogrel in patients with atrial fibrillation. Arch Intern Med 2010; 170(16):1433-1441

51 Ray WA, Chung CP, Murray KT, et al. Association of oral anticoagulants and proton pump inhibitor cotherapy with hospitalization for upper gastrointestinal tract bleeding. JAMA 2018;320 (21):2221-2230

52 Frey PM, Méan M, Limacher A, et al. Physical activity and risk of bleeding in elderly patients taking anticoagulants. J Thromb Haemost 2015;13(02):197-205

53 Tomaselli GF, Mahaffey KW, Cuker A, et al. 2017 ACC expert consensus decision pathway on management of bleeding in patients on oral anticoagulants: a report of the American College of Cardiology Task Force on Expert Consensus Decision Pathways. J Am Coll Cardiol 2017;70(24):3042-3067

54 Kaatz S, Ahmad D, Spyropoulos AC, Schulman S; Subcommittee on Control of Anticoagulation. Definition of clinically relevant nonmajor bleeding in studies of anticoagulants in atrial fibrillation and venous thromboembolic disease in non-surgical patients: communication from the SSC of the ISTH. J Thromb Haemost 2015;13(11):2119-2126

55 Pollack CV Jr, Reilly PA, Eikelboom J, et al. Idarucizumab for dabigatran reversal. N Engl J Med 2015;373(06):511-520

56 Connolly SJ, Milling TJ Jr, Eikelboom JW, et al; ANNEXA-4 Investigators. Andexanet alfa for acute major bleeding associated with factor Xa inhibitors. N Engl J Med 2016;375(12):1131-1141

57 Staerk L, Fosbøl EL, Lamberts M, et al. Resumption of oral anticoagulation following traumatic injury and risk of stroke and bleeding in patients with atrial fibrillation: a nationwide cohort study. Eur Heart J 2018;39(19):1698-1705a

58 Nielsen PB, Larsen TB, Skjøth F, Gorst-Rasmussen A, Rasmussen LH, Lip GY. Restarting anticoagulant treatment after intracranial hemorrhage in patients with atrial fibrillation and the impact on recurrent stroke, mortality, and bleeding: a nationwide cohort study. Circulation 2015;132(06):517-525

59 Murthy SB, Gupta A, Merkler AE, et al. Restarting anticoagulant therapy after intracranial hemorrhage: a systematic review and meta-analysis. Stroke 2017;48(06):1594-1600 